\title{
The 3' terminal sequence of the inosine monophosphate dehydrogenase gene encodes an active domain in the yeast Schizosaccharomyces pombe
}

\author{
Semian Karaer $^{1}$, Aysegül Topal Sarikaya ${ }^{1,2}$, Nazli Arda ${ }^{1,2}$ and Güler Temizkan ${ }^{1,2}$ \\ ${ }^{1}$ Department of Molecular Biology and Genetics, Faculty of Science, Istanbul University, Vezneciler, \\ Istanbul, Turkey. \\ ${ }^{2}$ Research and Application Center for Biotechnology and Genetic Engineering, Istanbul University, \\ Vezneciler, Istanbul, Turkey.
}

\begin{abstract}
The gua1 gene encoding inosine monophosphate dehydrogenase (IMPDH), which catalyses the first step in de novo biosynthesis of guanosine monophosphate (GMP), was cloned in the yeast Schizosaccharomyces pombe by functional complementation of a gua1ura4-D18 mutant strain from a S. pombe DNA genomic library. Complementation analysis revealed a $1.2 \mathrm{~kb}$ fragment which segregation analysis confirmed did not code for a suppressor gene. Only 446 nucleotides of the gua1 gene encoding the IMPDH C-terminal residues were found within this $1.2 \mathrm{~kb}$ sequence (GenBank, AJ293460). The comparison of this wild-type fragment with the same fragment from the gua1ura4-D18 mutant revealed that there was a point mutation at position 1261 (guanine $\rightarrow$ adenine) from the 5' end, corresponding to the amino acid residue 421 (glycine $\rightarrow$ serine) of the enzyme. Dot and Northern analyses showed that the gua 1 gene was expressed in transformants as well as in the wild-type and the gua1ura4-D18 mutant, but enzyme activity was only detected in wild-type and transformant cells. It seems likely that a 446 bp fragment from the 3' end of the gua1 gene abolished the point mutation in the mutant strain, suggesting that this fragment participates in the sequences encoding the active domain of IMPDH in S. pombe.
\end{abstract}

Key words: Schizosaccharomyces pombe, inosine monophosphate dehydrogenase, gual gene, purine nucleotide pathway.

Received: July 4, 2005; Accepted: December 16, 2005.

\section{Introduction}

The de novo biosynthesis of purine nucleotides is essentially the same in all groups of organisms studied so far (Henderson and Paterson, 1973; Michal, 1999) and inosine monophosphate dehydrogenase (IMPDH; E.C.1.1.1.205) is one of the key enzymes for the regulation of this pathway. This enzyme catalyses the NAD-dependent conversion of inosine monophosphate (IMP), which serves as a branch point between the adenine and guanine specific branches, to xanthosine monophosphate (XMP) which is the rate-limiting step in de novo guanine nucleotide biosynthesis (Hedstrom, 1999). Inhibition of IMPDH causes a reduction in the guanine nucleotide pool with subsequent interruption of DNA and RNA synthesis which results in cytotoxicity. The reduction in guanine nucleotides also compromises the ability of G-proteins to function as transducers of intracellular signals (Manzoli et al., 1995). In-

Send correspondence to Semian Karaer. Department of Molecular Biology and Genetics, Faculty of Science, Istanbul University, 34118 Vezneciler, Istanbul, Turkey. E-mail: semka @ istanbul. edu. tr. creased IMPDH activity and consequently GMP synthesis has been shown in a variety of cancer cell lines and it appears that IMPDH may be a target for cancer chemotherapy and the development of immunosuppressive drugs (Weber, 1983). The structural and functional properties of IMPDHs from different organisms and its mode of action and inhibition have been well documented (Hedstrom, 1999) and IMPDH sequences from at least 163 organisms from bacteria to plants have been reported to GenBank (http://www. ncbi.nlm.nih.gov/sutils/blink.cgi?pid=39959).

The yeast Schizosaccharomyces pombe is an attractive model system for eukaryotic cell and molecular biology studies. This yeast is known to have 12 loci (adel to ade10 plus gual and gua2) involved in the de novo biosynthesis of purine nucleotides (Heslot, 1972). The chromosomal location of all these genes have been determined and the ade1, ade2, ade4, ade6 and ade10 genes have been cloned and sequenced (McKenzie et al., 1987; Szankasi et al., 1988; Speiser et al., 1992; Ludin et al., 1994; Liedtke et al., 1998). Pourquie (1974) conducted the first study of the genes belonging to the $S$. pombe guanine nucleotide biosynthesis pathway and identified two types of genetically 
unlinked auxotrophic mutants designated gual and gua2, the gual mutant having no IMPDH activity. Haploidization and tetrad analyses showed that the gual gene was located at the centromeric region of chromosome II (Oraler et al., 1990).

During the study described in this paper we used complementation techniques to clone a partial gual gene from a $S$. pombe genomic library and, interestingly, found that the transformant containing only a 446 bp long fragment from the 3' end of the gene was able to produce an active enzyme.

\section{Material and Methods}

\section{Strains, plasmids and growth conditions}

The Schizosaccharomyces pombe wild-type strains $972 \mathrm{~h}^{-}$and $975 \mathrm{~h}^{+}$plus the IMPDH-negative gual mutant and the ura4-D18 mutant containing a full deletion of the ura4 gene (Grimm et al., 1988) were obtained from Istanbul University, Molecular Biology Laboratory collection (Address Above). All the $S$. pombe strains were grown using minimal media (MM) or enriched media (EM) broth or agar and sporulated in synthetic sporulation agar (SPA) as previously described by Gutz et al. (1974). The media were supplemented with guanine and uracil $(50 \mathrm{mg} / \mathrm{L})$ as required.

Two types of plasmid were used, the pUR19 yeast shuttle cloning vector and the pUC18 bacterial cloning vector. The Escherichia coli DH5 $\alpha$ was used for plasmid amplification. DNA manipulations, including plasmid preparation, subcloning, restriction mapping, agarose gel electrophoresis, and transformation and E. coli growth techniques were performed according to standard protocols (Sambrook et al., 1989). All enzymes for restriction mapping and subcloning were obtained from MBI Fermentas (Lithuania).

\section{Gene isolation and subcloning}

The gual gene was isolated by complementation using an $S$. pombe genomic library established in pUR19 (provided by Dr. Clive Price, University of Sheffield, Department of Molecular Biology and Biotechnology). To obtain the gualura4-D18 double-mutant, strains were crossed on SPA and the double-mutant selected from tetrads according to its guanine and uracil requirements. The mating type of the double-mutant was determined as described by Leupold (1970) and was transformed using $3.5 \mu \mathrm{g}$ of DNA for each experiment (Warshawsky and Miller, 1994). Plasmids from transformants were rescued according to the protocol of Topal et al. (1997). To determine the smallest fragment containing the gual gene, subcloning was performed in pUR19 and plasmids were transformed into the gualura4-D18 mutant strain.

\section{Suppressor gene analysis, sequencing and RNA isolation and analysis}

Randomly selected $S$. pombe transformants carrying the insert in their genome were crossed with the wild-type $975 \mathrm{~h}^{+}$and genotypes of the spores were determined on selective media by tetrad analysis (McKenzie et al., 1987).

For sequencing, the smallest DNA fragment carrying the gual gene (determined by complementation) was cloned to pUC18. Sequencing reactions of this fragment and the PCR product of the mutant allele from the gual strain were performed using a Pharmacia Fluorescence Kit and a Perkin Elmer model 377 automatic DNA sequencer with a universal M13 reverse primer followed by primers, corresponding to the internal sequences of the insert. Sequence analysis of the insert was evaluated using the UWGCG (University of Wisconsin Genetic Computer Group) programs. A search of the GenBank database was made using the NCBI BLASTP 2.2.5 program (Altschul et al., 1997).

Total RNA was isolated as described by Burke et al. (2000) and dot and Northern hybridizations performed using the DNA Labeling and Detection (DIG) Kit according to the manufacturer's instructions (Boehringer Mannheim). The RNA samples $(\sim 10 \mu \mathrm{g})$ were blotted on a nylon membrane (Schleicher \& Schuell) for dot hybridization and the RNAs separated on $1.2 \%(\mathrm{w} / \mathrm{v})$ agarose gel containing 0.66 $\mathrm{M}$ formaldehyde and $0.5 \mu \mathrm{g} / \mathrm{mL}$ ethidium bromide and transferred to the membrane using a capillary system. A DIG-11-dUTP labeled DNA fragment carrying the gual gene was used as a probe for hybridizations.

\section{Inosine monophosphate dehydrogenase (IMPDH) assay}

We prepared $S$. pombe lysates according to the method of Pourquié (1974), with a slight modification. Cells were grown in EM broth to the late log phase in a rotary shaker $\left(30^{\circ} \mathrm{C}, 150 \mathrm{rpm}\right)$, harvested by centrifugation for $10 \mathrm{~min}$ at $0{ }^{\circ} \mathrm{C}$ and $4000 \mathrm{x} g$, washed twice in distilled water, re-centrifuged. The pellet was resuspended in $1.5 \mathrm{~mL}$ of breakage buffer (1 M Tris-HCl, $\mathrm{pH} 8.4 ; 0.1 \mathrm{M}$ $\mathrm{KCl})$ per gram of cell wet-weight and $0.45-0.50 \mathrm{~mm} \varnothing$ glass beads were added to just below the meniscus of the suspension and the mixture homogenized in a cell Braun homogenizer chilled with $\mathrm{CO}_{2}$ at $15 \mathrm{~s}$ intervals for three minutes. After cell disruption, the homogenate was clarified by ultra-centrifugation for $90 \mathrm{~min}$ at $4{ }^{\circ} \mathrm{C}$ and $90000 \mathrm{x}$ $g$ and the resultant supernatant (crude extract) was used for the enzyme assay. Protein concentration of the crude extract was measured by the method of Lowry et al. (1951) and IMPDH activity was determined spectrophotometrically by monitoring the formation of NADH at $340 \mathrm{~nm}$ (Carr et al., 1993) by adding $0.9 \mathrm{~mL}$ of crude extract to $4.1 \mathrm{~mL}$ of reaction mixture $(100 \mathrm{mM}$ Tris- $\mathrm{HCl}, \mathrm{pH} 8.0$, $100 \mathrm{mM} \mathrm{KCl}, 3 \mathrm{mM}$ EDTA, $200 \mu \mathrm{M}$ inosine mono- 


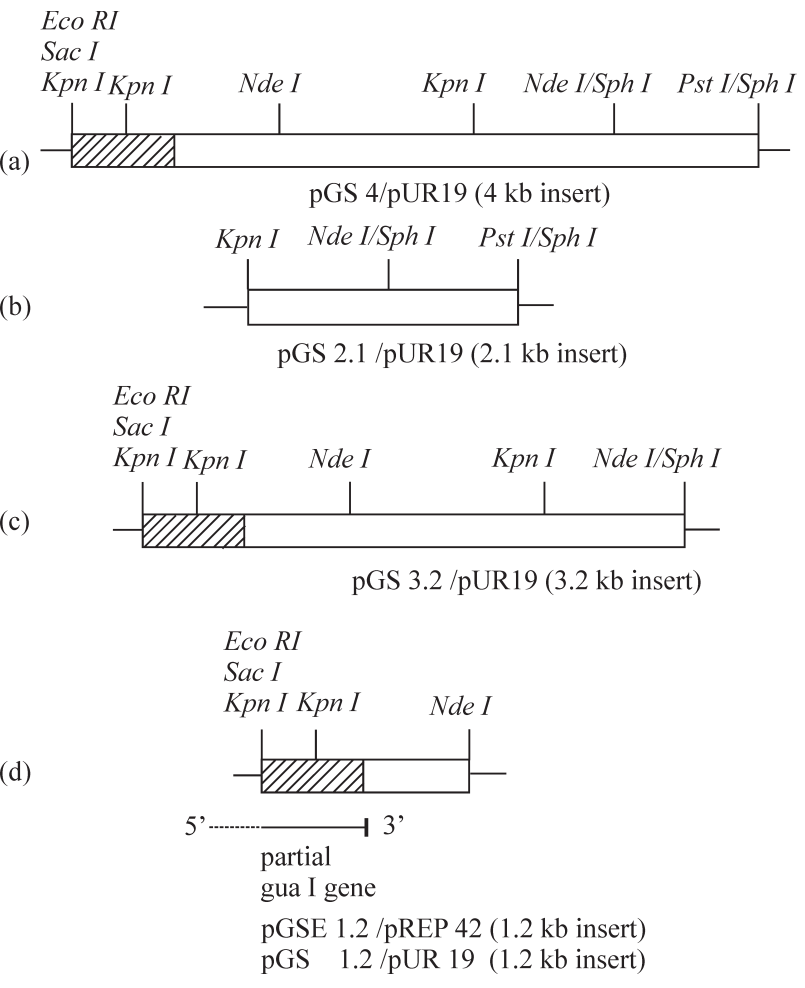

Figure 1 - The cloned 4kb Schizosaccharomyces pombe fragment in plasmid pUR19 containing a partial gual gene (a) and three subclones (b-d). Subclone pGS1.2 contained the shortest (1.2 kb) DNA fragment that complements the gual mutant. The position and orientation of the partial gual gene is represented by the hatched box and arrow.

phosphate (IMP) and $400 \mu \mathrm{M}$ NAD) and a second reaction mixture supplemented with $0.12 \mathrm{mM}$ allopurinol, a potent inhibitor of IMPDH (O'Gara et al., 1997). After incubation at $37{ }^{\circ} \mathrm{C}$ for $15 \mathrm{~min}$, the optical density was read at $\lambda=340 \mathrm{~nm}\left(\mathrm{OD}_{340}\right)$ against a blank consisting of breakage buffer minus crude extract. Enzyme activity was expressed as $\mathrm{OD}_{340}$ per mg per $\mathrm{mL}$ of protein in the crude extract.

\section{Results}

\section{Cloning of the gua1 gene}

The $S$. pombe gualura4-D18 strain was transformed with a pUR19/Sau3A genomic library and cells exhibiting $\mathrm{gua}^{+} \mathrm{ura}^{+}$phenotype were selected. Five positive colonies were obtained from approximately $3.6 \times 10^{4}$ transformants. The plasmids from these transformants were isolated and amplified in E. coli, and their sizes were determined by restriction analysis. These plasmids were named according to the size of insert as (in sequence) pGS9.3, pGS7.5, pGS4.8 (two plasmids of similar size) and pGS4. The plasmid used for further studies was pGS4. To determine the location of the gual gene within the $4 \mathrm{~kb}$ insert, the gualura4-D18 double-mutant was transformed with several subcloned DNA fragments of variable lengths. The smallest fragment complementing the mutation was a $1.2 \mathrm{~kb} K p n \mathrm{I} / \mathrm{NdeI}$ fragment (Figure 1). Then, this fragment was cloned into
pUR19. New construct was designated as pGS1.2, and the positive $S$. pombe transformants designated as SG1.

\section{Suppressor gene analysis}

Suppressor gene analysis was performed to determine whether the $1.2 \mathrm{~kb} \mathrm{KpnI} / \mathrm{NdeI}$ fragment contained the gual gene itself or an extragenic suppressor. The segregation of the gual gene localized on chromosome II (Oraler et al., 1990) with the ura4 gene localized on chromosome III (Gygax and Thuriaux, 1984) was investigated. To achieve this the wild-type $S$. pombe $975 \mathrm{~h}^{+}$strain was crossed with the stable SG1 S. pombe transformant, which carries the gual gene integrated into its genome. We analyzed 556 spores from 139 tetrads for guanine and uracil auxotrophy and found that 43 spores were $u \mathrm{ra}^{-}$and all of them were $\mathrm{gua}^{+}$. This indicated that the insert had integrated precisely at the gual locus and that the complementation did not originate from a suppressor gene, but instead represented a cloned functional gual gene.

\section{Sequence analysis}

We cloned a $1.2 \mathrm{~kb} K p n \mathrm{I} / \mathrm{NdeI}$ DNA fragment carrying the gual gene into pUC18 and the new construct (pGSC1.2) was transformed in E. coli DH5 $\alpha$ as described above. The DNA sequence of the fragment was analyzed and compared with the sequence present in cosmid c2F12 which is assumed to be carrying the putative gual gene and which is available at the $S$. pombe genome project in the Sanger Center (http://srs6.ebi.ac.uk/srsbin/cgi-bin/wgetz? -id+3HhqU1NNOGG+-e+[EMBL: 'SPBC2F12']+-qnum+ $1+$-enum+12). We were surprised to find that the whole gual gene did not exist within the cloned $1.2 \mathrm{~kb}$ fragment but only a $446 \mathrm{bp}$ long region from the 3' terminus of the gual gene was located in this insert, the remaining approximately $750 \mathrm{bp}$ belonged to the gene encoding a kinesinelike protein. This partial sequence of the gual gene has been deposited in the National Center for Biotechnology Information (NCBI) data bank under the Accession Number AJ293460. Sequence identity comparisons showed that this partial gene fragment was correlated with the C-terminal residues of the enzyme, the partial sequence revealing an open reading frame of 446 nucleotides encoding a polypeptide of 148 amino acids (Figure 2).

The size of the IMPDH gene PCR products from wild and mutant strains was also similar, leading us to determine the mutation type of the gual strain. The results of the sequence analysis of the wild-type and mutant strain proved that the defect within the gual gene was a point mutation at position 1261 (ggt $\rightarrow$ agt), resulting a substitution at residue 421 (glycine $\rightarrow$ serine) in $S$. pombe IMPDH. Thus a $446 \mathrm{bp}$ from the 3 ' terminus of the gene complemented with this mutation whereas PCR product of the remaining longer 1129 bp part did not (Figure 2).

A search of the GenBank database using NCBI BLASTP 2.2.5 program (Altschul et al., 1997) showed that 


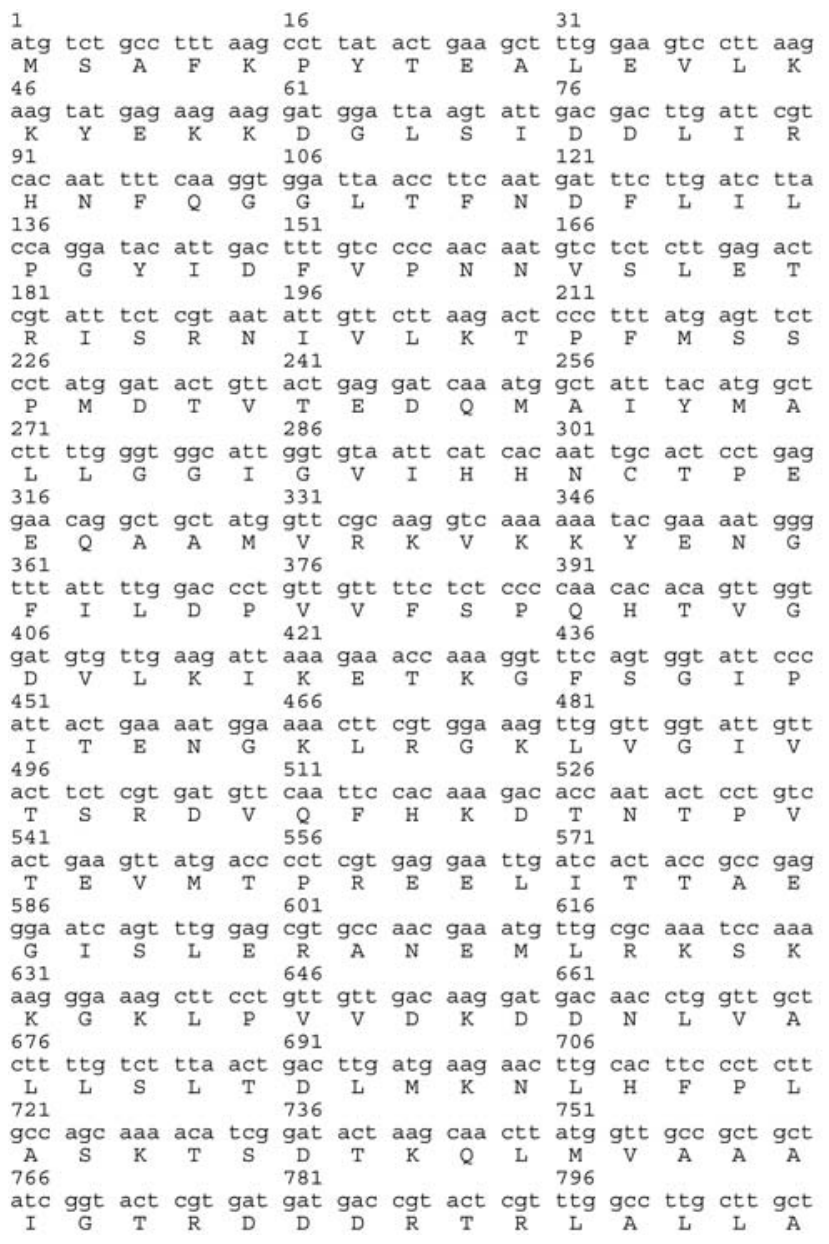

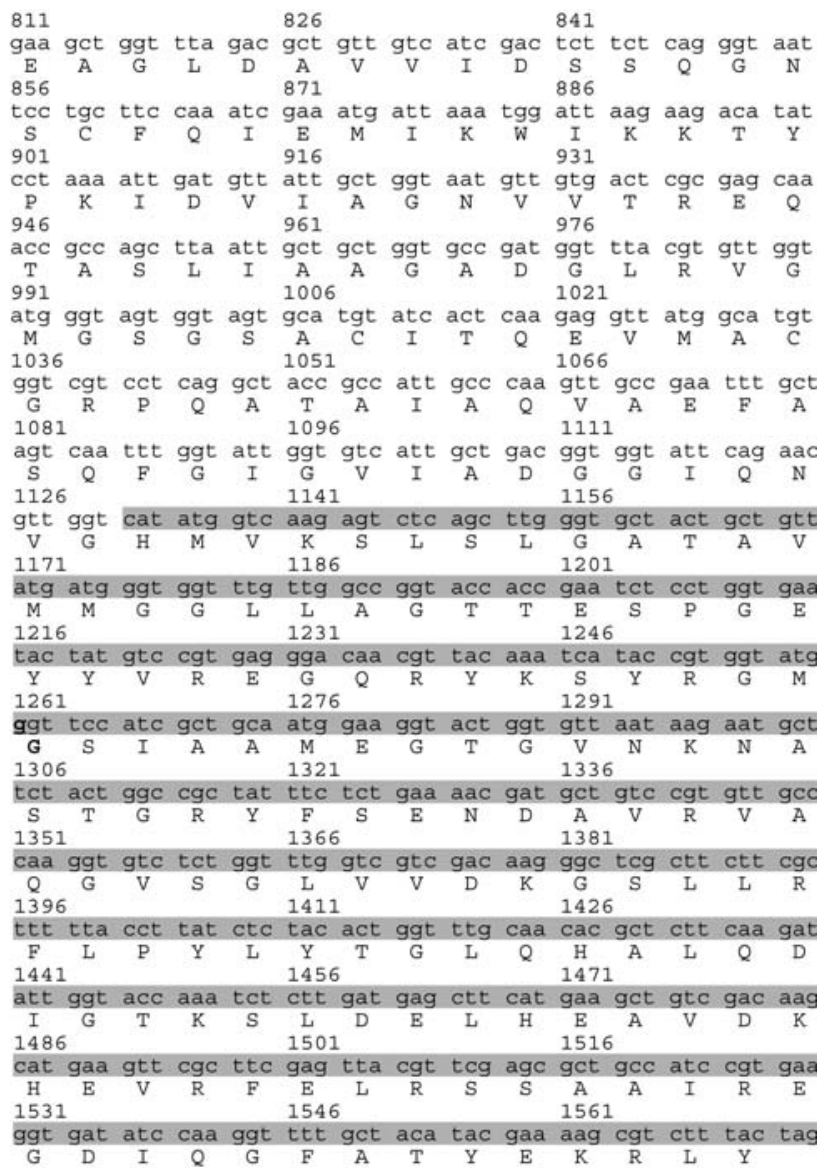

Figure 2 - The sequence of the Schizosaccharomyces pombe gual gene showing the predicted inosine monophosphate dehydrogenase (IMPDH) amino acid residues. The cloned and complemented partial gual gene discovered in this study is shadowed. The location of the point mutation is shown in boldfaced type. Altering the guanine $(\mathrm{g})$ at the 1261 nucleotide position to adenine (a) caused the IMPDH $421_{\text {Gly }}$ residue to be substituted by a $421_{\text {Ser }}$ residue.

the partial IMPDH amino acid sequence had homologies with IMPDH from Candida albicans (64\%), Saccharomyces cerevisiae (62\%), Drosophila melanogaster (53\%), human type I (53\%), Mus musculus type I (52\%), human type II (52\%), M. musculus type II (52\%) Arabidopsis thaliana (45\%) and E. coli (40\%) (Figure 3).

\section{Transcription analysis}

To demonstrate expression of the gual gene we isolated RNAs from three different types of the cells, wildtype, double-mutant (gualura4-D18) and the transformant (SG1). Dot and Northern hybridizations were carried out with a $1.2 \mathrm{~kb}$ fragment as a probe containing partial gene fragments of a kinesine-like protein and IMPDH. Labeling was detected with the samples tested by dot hybridization (data not shown) and two bands were observed for all samples in the Northern blot hybridizations (Figure 4). One of these bands was consistent with the size of a full-length $S$. pombe IMPDH transcript of 1575 nucleotides, indicating that expression of this gene occurred at the transcriptional level in the double mutant. The size of the other band, cor- responding to the kinesine-like protein transcript was about $2 \mathrm{~kb}$.

\section{Enzyme assay}

The IMPDH activities of the crude extracts from the $972 \mathrm{~h}^{-}$wild-type, gualura4-D18 double-mutant and the SG1 transformant were determined in the reaction mixture with or without the IMPDH inhibitor allopurinol. Significant IMPDH activity existed in wild-type and the SG1 transformant but almost none in the gualura4-D18 mutant and there was also a clear difference between the activities detected for each sample in the presence and absence of allopurinol. These results confirmed that allopurinol had an inhibitory effect on IMPDH in vitro (Weber, 1983) and decreased the enzyme activity (Table 1).

\section{Discussion}

We found that the S. pombe DNA fragment cloned in this study is part of the IMPDH gene as indicated by complementation with the gualura4-D18 double- mutant as well as comparison of the sequence of the fragment with 


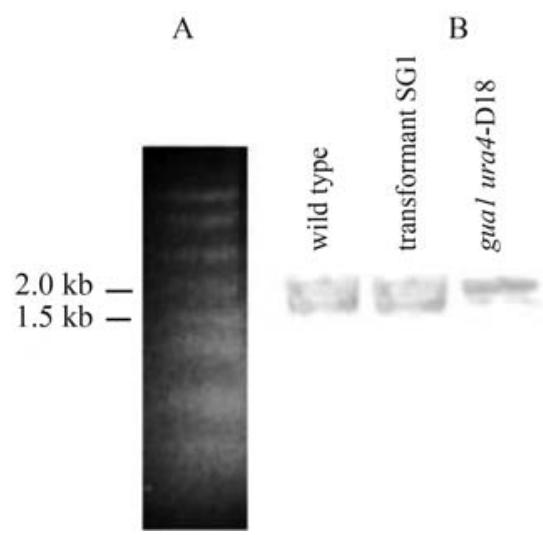

Figure 3 - Northern blot analysis of inosine monophosphate dehydrogenase (IMPDH) transcripts in the Schizosaccharomyces pombe wild-type, mutant and SG1 transformant. Total RNA $(\sim 10 \mu \mathrm{g})$ was separated using denaturing formaldehyde/agarose gel electrophoresis. RNA markers separated on agarose gel (a); Northern blot hybridization of IMPDH mRNA with a DIG-11-dUTP labeled DNA fragment carrying the gual gene as a probe.

the putative gual gene cloned to chromosome II cosmid c2F12.

The BLASTP search of the GenBank database showed that the partial IMPDH amino acid sequence had 40 to $64 \%$ homology with IMPDH from, in increasing order of size, E. coli, A. thaliana, M. musculus type II, human type II, Mus musculus type I, Drosophila melanogaster, $S$. cerevisiae and C. albicans (Figure 3), indicating that this sequence seems to be conserved between unrelated species.

The observation of similar-sized IMPDH mRNAs in both the wild-type and the mutant $S$. pombe strain indicated that the defect of the gual gene was due to a point mutation. Furthermore, sequence analyses showed that the point mu-
Table 1 - Inosine monophosphate dehydrogenase (IMPDH) activity $\left(\mathrm{OD}_{340}\right.$ per mg per $\mathrm{ml}$ of protein) in crude extracts of Schizosaccharomyces pombe. Activity measurements were carried out using two different reaction mixtures, one with allopurinol (O'Gara et al., 1997) and the other without allopurinol (Carr et al., 1993). Values represent the average \pm the standard deviation for three independent determinations.

\begin{tabular}{lcc}
\hline & \multicolumn{2}{c}{ IMPDH activity } \\
\cline { 2 - 3 } Cell type & With allopurinol & Without allopurinol \\
\hline Wild type $\left(972 \mathrm{~h}^{-}\right)$ & $0.465 \pm 0.057$ & $0.759 \pm 0.015$ \\
$\begin{array}{l}\text { Double mutant } \\
\text { gualura4-D18) }\end{array}$ & $0.061 \pm 0.008$ & $0.045 \pm 0.003$ \\
Transformant (SG1) & $0.408 \pm 0.009$ & $0.549 \pm 0.014$ \\
\hline
\end{tabular}

tation was exactly at position 1261 (ggt $\rightarrow$ agt), the first nucleotide of codon 421 which encodes a glycine residue in IMPDH (Figure 2), and that this mutation changed this residue to a serine residue.

There was significant enzyme activities in both the wild-type strain and the SG1 transformant but the enzyme activity in the mutant was so low that it could be disregarded. These results show that the SG1 transformant containing the partial gual gene showed nearly as much catalytic activity as wild-type $S$. pombe. In addition, when we cloned the rest of the gene (1129 bp) into the gualura4D18 double-mutant, no complementation was observed. Having shown that the enzyme activity obviously originated from one of the IMPDH C-terminal residues encoded by a small portion of gual gene, complementing the mutation raised the interesting question of how only a partial gene sequence could give rise to a level of IMPDH expression similar to that of the wild-type $S$. pombe.

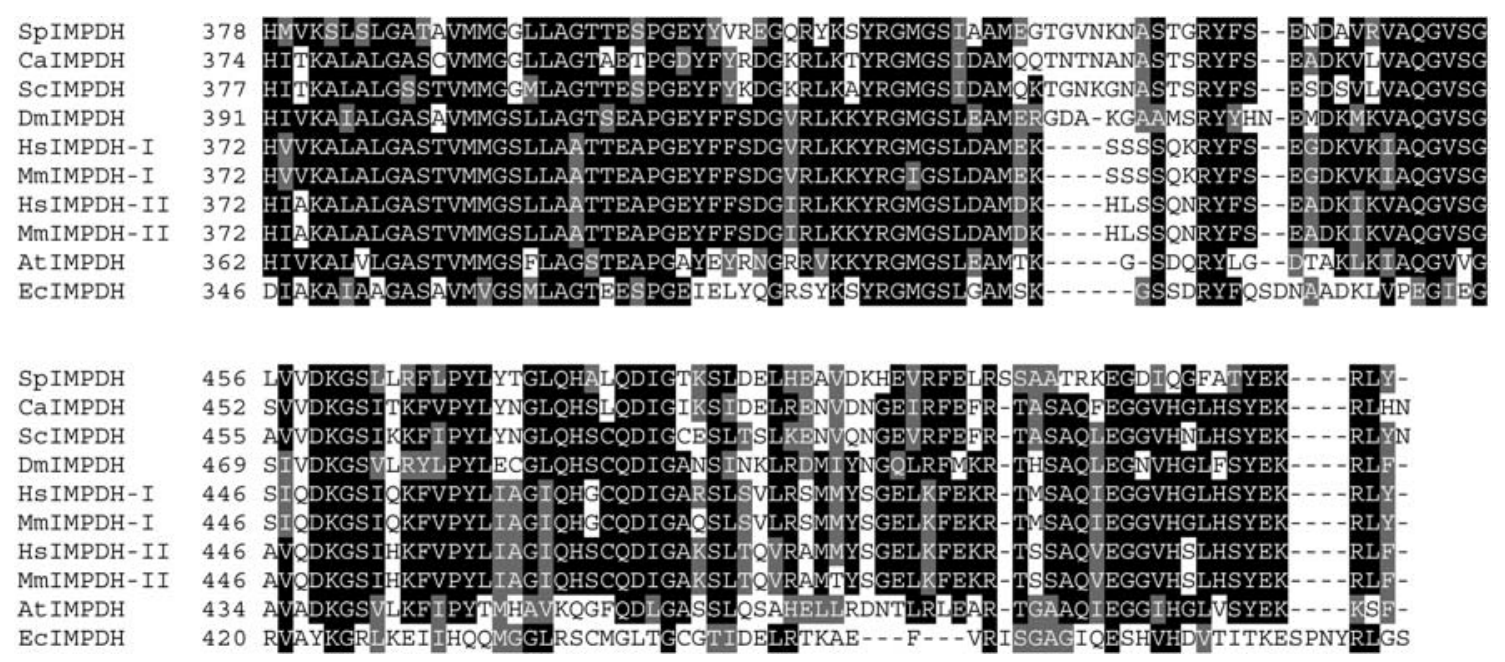

Figure 4 - Partial amino acid alignment of Schizosaccharomyces pombe inosine monophosphate dehydrogenase (IMPDH) (GenBank CAB97003) homologues with Candida albicans (O00086), Saccharomyces cerevisiae (P50094), Drosophila melanogaster (Q07152) Human type I (P20839), Mus musculus (P50096), Human type II (P12268), M. musculus type II (P24547), Arabidopsis thaliana (Q9SA34) and Escherichia coli (P06981). Abbreviations for the species are: $\mathrm{Sp}=S$. pombe $; \mathrm{Ca}=$ C. albicans $; \mathrm{Sc}=S$. cerevisiae $; \mathrm{Dm}=$ D. melanogaster $; \mathrm{Hs}=$ Homo sapiens $; \mathrm{Mm}=$ M. musculus $;$ At $=$ A. thaliana; $\mathrm{Ec}=$ E. coli. Identical amino acids are shown with a black background, similar amino acids with a gray background. Dashes (gaps) have been introduced for optimal alignment. The alignments revealed that the regions of putative catalytic domain amino acids (378-524) were highly conserved. 
The IMPDH enzyme is a tetramer formed by monomers consisting of two domains, an $\alpha / \beta$ barrel core domain (catalytic domain) and a cystathione- $\beta$-synthase (CBS) subdomain (Carr et al., 1993; Huete-Perez et al., 1995; Zhou et al., 1997; Colby et al., 1999; Zhang et al., 1999). Zhang et al. (1999) showed that site specific mutations in the CBS subdomain of Streptococcus pyrogenes did not result in loss of IMPDH activity but the construction of a point mutation in the active site by changing $\mathrm{Arg}_{406}$ to alanine resulted in complete loss of IMPDH activity. However it had been previously reported (Zhou et al., 1997) that IMPDH from Borrelia burgdorferi did not contain a CBS subdomain and yet maintained enzymatic activity. Nimmesgern et al. (1999) demonstrated the expression of the core domain and the CBS subdomain of human IMPDH separately in E. coli and determined that the core domain was enzymatically active while the CBS subdomain was inactive. Futer et al. (2002) reported that the mutations of three active site residues to alanine in the IMP binding pocket reduced IMPDH activity to less than $0.1 \%$ of that found in human wild-type IMPDH.

All these findings suggest that the region close to the $\mathrm{C}$ terminus of the core domain, rather than the CBS subdomain, is responsible for IMPDH activity. Our results were also consistent with this conclusion because the SG1 transformant contained a $446 \mathrm{bp}$ fragment of the gene encoding the IMPDH C-terminal residues and was capable of producing active enzyme.

However, IMPDH CBS subdomains from different species vary considerably in size and the subdomain sequences are much less conserved than the core domain sequences (Nimmesgern et al., 1999). Moreover, mutation studies on the gene fragment encoding the CBS domain in Methanococcus janaschii (Archeae) suggest that the CBS domain is responsible for the regulation of cystathione$\beta$-synthase activity (Bateman, 1997). Thus it can be speculated that the function of the $S$. pombe IMPDH CBS domain may also be related to regulation of IMPDH expression. However, the presence of this domain in the alignment of all but one (from B. burgdorferi) of the 56 IMPDHs studied by Nimmesgern et al. (1999) still raised questions with regarding its functional role.

In our study, complementation in the SG1 transformant carrying the $446 \mathrm{bp}$ part of the gual gene in the plasmid pGS1.2 suggested that the insert integrated into the exact region containing the mutation in the genome by homologous recombination. Hence, it can be concluded that a $446 \mathrm{bp}$ from the 3' end of gual gene participates in the sequences encoding the catalytic domain of $S$. pombe IMPDH.

\section{Acknowledgments}

We appreciate the critical comments on the manuscript by D.E. Kelly. We are grateful to Gökhan Akman for help with the alignment. This work was supported by the Research Fund of The University of Istanbul (Project numbers T-404/270697, B-280/200899 and B-1016/07062001) and by the Research and Application Center for Biotechnology and Genetic Engineering (Project number BIYOGEM-98/01).

\section{References}

Altschul SF, Madden TL, Schäffer AA, Zhang J, Zang Z, Miller W and Lipman DJ (1997) Gapped BLAST and PSI-BLAST: A new generation of protein database search programs. Nucleic Acids Res 25:3389-3402.

Bateman A (1997) The structure of a domain common to archaebacteria and the homocystinuria disease protein. Trends Biochem Sci 22:12-13.

Burke D, Dawson D and Stearns T (2000) Methods in Yeast Genetics. Cold Spring Harbor Laboratory Press, New York, 205 pp.

Carr SF, Papp E, Wu JC and Natsumeda Y (1993) Characterization of human type I and type II IMP dehydrogenases. J Biol Chem 268:27286-27290.

Colby TD, Vanderveen K, Strickler MD, Markham GD and Goldstein BM (1999) Crystal structure of human type II inosine monophosphate dehydrogenase: Implications for ligand binding and drug design. Proc Natl Acad Sci USA 96:3531-3536.

Futer O, Sintchak MD, Caron PR, Nimmesgern E, DeCenzo MT, Livingston DJ and Raybuck SA (2002) A mutational analysis of the active site of human type II inosine 5'-monophosphate dehydrogenase. Biochim Biophys Acta 1594:27-39.

Grimm C, Kohli J, Murray J and Maundrell K (1988) Genetic engineering of Schizosaccharomyces pombe: A system for gene disruption and replacement using the ura4 gene as a selectable marker. Mol Gen Genet 215:81-86.

Gutz H, Heslot H, Leupold U and Loprieno N (1974) Schizosaccharomyces pombe. In: King RC (ed) Handbook of Genetics. Plenum Press, New York, pp 395-446.

Gygax A and Thuriaux P (1984) A revised chromosome map of the fission yeast Schizosaccharomyces pombe. Curr Genet 8:85-92.

Hedstrom L (1999) IMP dehydrogenase: Mechanism of action and inhibition. Current Med Chemistry 6:545-560.

Henderson JF and Paterson ARP (1973) Nucleotide Metabolism. Academic Press, New York, pp 207-263.

Heslot H (1972) Genetic control of the purine nucleotide pathway in Schizosaccharomyces pombe. Proc IV IFS/Ferment Technol Today 867-876.

Huete-Perez JA, Wu JC, Whitby FG and Wang CC (1995) Identification of the IMP binding site in the IMP dehydrogenase from Tritrichomonas foetus. Biochem 34:13889-13894.

Leupold U (1970) Genetical methods for Schizosaccharomyces pombe. In: Prescott DM (ed) Methods in Cell Physiology, v. 4. Academic Press, New York, pp 169-177.

Liedtke C and Schmidt H (1998) Molecular cloning and sequence analysis of the Schizosaccharomyces pombe ade $10^{+}$gene. Yeast 14:1307-1310.

Lowry OH, Rosebrough NJ, Farr AL and Randall RJ (1951) Protein measurement with the Folin-phenol reagent. J Biol Chem 193:265-275. 
Ludin KM, Hilti N and Schweingruber ME (1994) The ade4 gene of Schizosaccharomyces pombe: Cloning, sequence and regulation. Curr Genet 25:465-468.

Manzoli L, Billi AM, Gilmour RS, Martelli AM, Matteucci A, Rubbini S, Weber G and cocco L (1995) Phosphoinositide signaling in nuclei of friend-cells-tiazofurin down-regulates phospholipase-C beta (1). Cancer Res 55:2978-2980.

McKenzie R, Schuchert P and Kilbey B (1987) Sequence of the bifunctional adel gene in the purine biosynthetic pathway of the fission yeast Schizosaccharomyces pombe. Curr Genet 12:591-597.

Michal G (1999) Biochemical Pathways: An Atlas of Biochemistry and Molecular Biology. John Wiley \& Sons Inc, New York, pp 99-102

Nimmesgern E, Black J, Futer O, Fulghum JR, Chambers SP, Brummel CL, Raybuck SA and Sintchak MD (1999) Biochemical analysis of the modular enzyme inosine 5'-monophosphate dehydrogenase. Protein Expr Purif 17:282-289.

O'Gara MJ, Lee C-H, Weinberg GA, Nott JM and Queener SF (1997) IMP dehydrogenase from Pneumocystis carinii as a potential drug target. Antimicrob Agents Chemother 41:4048 .

Oraler G, Olgun A and Karaer S (1990) An addition to the chromosome map of Schizosaccharomyces pombe: The localization of gua genes. Curr Genet 17:543-545.

Pourquié MJ (1974) Controle génétique du métabolisme purique chez la levure Schizosaccharomyces pombe. Ph.D. Thesis L’Université Paris VI, Paris.
Sambrook J, Fritsch EF and Maniatis T (1989) Molecular Cloning: A Laboratory Manual. Cold Spring Harbor Laboratory Press, New York.

Speiser DM, Ortiz DF, Kreppel L, Scheel G, McDonald G and Ow DW (1992) Purine biosynthetic genes are required for cadmium tolerance in Schizosaccharomyces pombe. Mol Cell Biol 12:5301-5310.

Szankasi P, Heyer WD, Schuchert P and Kohli J (1988) DNA sequence analysis of the ade6 gene of Schizosaccharomyces pombe. Wild-type and mutant alleles including the recombination host spot allele ade6-M26. J Mol Biol 204:917-925.

Warshawsky D and Miller L (1994) Improved method for rapid transformation of intact Schizosaccharomyces pombe cells. Biotechniques 16:798-800.

Weber G (1983) Biochemical strategy of cancer cells and the design of chemotherapy: G.H.A. Clowes memorial lecture. Cancer Res 43:3466-3492.

Zhang R-G, Evans G, Rotella FJ, Westbrook EM, Beno D, Huberman E, Joachimiak A and Collart FR (1999) Characteristics and crystal structure of bacterial inosine-5' -monophosphate dehydrogenase. Biochemistry 38:4691-4700.

Zhou X, Cahoon M, Rosa P and Hedstrom L (1997) Expression, purification, and characterization of inosine-5'-monophosphate dehydrogenase from Borrelia burgdorferi. J Biol Chem 272:21977-21981.

\section{Internet Resources}

Topal A, Karaer S and Temizkan G (1997) A simple method for rescuing autonomous plasmid from fission yeast. Technical Tips Elsevier Trends Journals. http://www.elsevier.com//locate/tt0.T01070.

Associate Editor: Sérgio Olavo Pinto da Costa 